\title{
Ingestion of bacteria expressing dsRNA to maggots produces severe mortality and deformities in fruit fly, Bactrocera dorsalis (Hendel) (Diptera: Tephritidae)
}

\author{
Prashant Mohanpuria ${ }^{* \dagger} \mathbb{D}$, Mohan Govindaswamy ${ }^{\dagger}$, Gurupkar Singh Sidhu, Sandeep Singh, Simranpreet Kaur and \\ Parveen Chhuneja
}

\begin{abstract}
Background: The oriental fruit fly, Bactrocera dorsalis (Hendel), is the world's most damaging (30-100\%) pest infesting important fruits and vegetables. Its control is highly challenging due to its polyphagous, multivoltine nature, and unexposed developmental stages. No known fruit fly-resistant guava germplasm is reported so far worldwide. RNAi approach in guava against fruit fly can provide an attractive alternative to overcome this problem.

Main body: Escherichia coli-based dsRNA expression strategy was used to investigate its potential in control of $B$. dorsalis via targeting its two vital genes, ecr (ecdysone receptor) and rp/19 (a ribosomal protein L19). Effects of feeding E. coli, HT115 (DE3) expressing dsRNA of Bdecr and Bdrp/19 with artificial diet to maggots of $B$. dorsalis resulted in severe mortality and deformities in treated maggots, emerged pupae, and adults. Total mortality (including deformity) of maggots, pupae, and adult fruit flies was $86.3 \%$ and $87.9 \%$ and was highest in $700 \mu l(x$ 200 of $3.5 \times 10^{8}$ cells) dsRNAs of Bdecr and Bdrp/19 bacterial treatment respectively, compared to 350 and $200 \mu \mathrm{l}$ bacterial treatments. Severe defects in terms of developmental changes like melanisation and deformities of maggots and pupae, absence of wings, underdeveloped abdomen/absence of complete abdomen, absence of legs, severely curled wings, malformed legs, and incomplete eclosion, and suppression of these target genes expression were observed in emerged adults.

Short conclusion: The study provides a proof of concept of feasibility to silence two potential genes by feeding bacteria expressing dsRNA in all developmental stages of $B$. dorsalis to step further to perform RNAi-based pest control.
\end{abstract}

Keywords: Fruit fly, Bactrocera dorsalis, RNAi, Bacteria expressing dsRNA, Deformity, Mortality

\section{Background}

The oriental fruit fly, Bactrocera dorsalis (Hendel) (Diptera: Tephritidae), is considered one of the most destructive pests of several economic fruits and vegetables throughout India and in whole of the South East Asia

\footnotetext{
* Correspondence: pmohanpuria@pau.edu

†Prashant Mohanpuria and Mohan Govindaswamy contributed equally to this work.

School of Agricultural Biotechnology, Punjab Agricultural University, Ludhiana 141004, India
}

\section{Springer Open}

and Pacific region resulted in huge economic losses (including quantitative and qualitative) (Wei et al. 2017). The fruit fly is a polyphagous pest having 117 host species in 76 genera and 37 families (Allwood et al. 1999). In India, three important fruit fly species, i.e., $B$. dorsalis (Hendel), B. correcta (Bezzi), and B. zonata (Saunders), attack mainly fruit crops. Out of these, $B$. dorsalis causes up to $80 \%$ crop losses in mango and guava (Verghese et al. 2002). Management of this pest is particularly difficult because of its polyphagous nature, unexposed
(0) The Author(s). 2021 Open Access This article is licensed under a Creative Commons Attribution 4.0 International License, which permits use, sharing, adaptation, distribution and reproduction in any medium or format, as long as you give appropriate credit to the original author(s) and the source, provide a link to the Creative Commons licence, and indicate if changes were made. The images or other third party material in this article are included in the article's Creative Commons licence, unless indicated otherwise in a credit line to the material. If material is not included in the article's Creative Commons licence and your intended use is not permitted by statutory regulation or exceeds the permitted use, you will need to obtain permission directly from the copyright holder. To view a copy of this licence, visit http://creativecommons.org/licenses/by/4.0/. 
developmental stages, and rapid population growth (Singh 2017). Fruit flies has traditionally been managed through various cultural practices, pesticides spray, bagging, postharvest techniques, and methyl eugenol baiting techniques but are not sufficient enough to tackle with this serious pest and thus, it is of great concern now (Verghese et al. 2002).

The present scenario warrants the need for RNAi as novel biotechnological approach for managing the fruit fly in fruit crops, which can further strengthen the existing IPM module for fruit flies. Presence of dsRNA corresponding to a target gene acts as a trigger for initiating RNAi mechanism in eukaryotes. RNAi has been widely accepted as a tool for gene knockdown and functional genomics studies but also has potential as a technology to control pest species (Tayler et al. 2019). The core RNAi machinery is conserved in all insect species and thus, by targeting essential genes, various physiological, developmental, and reproductive deformities in insect pests can be possible. The sequence specificity of endogenous RNAi pathway allows the targeted suppression of genes essential for insect survival and thus, offers the development of a specific, logical, and sustainable strategy to combat against insect pests. RNAi is a great technique for reducing gene expression and has been used for insect pests' management by several researchers (Tayler et al. 2019; Christiaens et al. 2020). Application of RNAi has been realized in coleopteran species, particularly in Western corn rootworm, a devastating pest impacting corn production in USA (Bachman et al. 2016). But there is no research work carried out in India on ingestion of bacteria expressing dsRNA or even direct extract of dsRNA of $B$. dorsalis-specific crucial genes and evaluation of its gene silencing effects in subsequently emerged developmental stages to improve RNAbased control.

DsRNA-based RNAi has been recognized as promising stable and powerful research tool for insect pest management (Joga et al. 2016). RNAi is a posttranscriptional, dsRNA-directed, sequence-specific degradation of target mRNA, which ultimately suppresses the production of a specific protein in any eukaryotic organism (Mohanpuria et al. 2011). In majority of the insects, research has mostly focused on non-cell autonomous (environmental and systemic) RNAi response. Notably, the silencing signals can be taken up and passed on even among cells to produce the effects where the target genes are absent (Winston et al. 2007). The ingestion through in planta expression or feeding or injection of double-stranded RNAs (dsRNA) targeting essential genes of insect pests trigger RNAi and led to growth inhibition, developmental aberrations, reduced fecundity, and mortality (Zhu et al. 2011).
Number of genes in adult $B$. dorsalis has been successfully silenced by injecting or feeding dsRNAs of selected target genes encoding female-specific double sex protein, rpl19, V-ATPase D subunit, fatty acid elongase Noa, small GTPase Rab11, spr, and spermatogenesis (Li et al. 2015; Dong et al. 2016). But feeding bacteria expressing dsRNA of target gene to maggots resulting severe observable deformities/mortality in maggot, pupal, and adult stages of $B$. dorsalis has not been reported so far.

Therefore, in the present study, two vital genes, i.e., ecr and rpl19 of B. dorsalis were selected for their silencing through RNAi because of their critical roles in normal growth, development, moulting, and metamorphosis of all insects. The ecdysone receptor is a liganddependent transcription factor which forms a heterodimer with another transcription factor, USP, and this activates the transcription of number of target genes (Billas et al. 2003). Functional ecdysone receptor is the product of ECR and USP genes in insects and thus coordinating the moulting and metamorphosis in insects through ecdysteroids hormone (Schwedes and Carney 2012). While the rpl19 gene which is acting as reference gene in gene expression studies, is one of the conserved housekeeping gene and encodes a ribosomal protein, RPL19, that is a component of the $60 \mathrm{~S}$ ribosomal subunit and belongs to the L19E family of ribosomal proteins (Zhou et al. 2010). Attempt has been made to silence ecr and rpl19 genes by feeding bacteria expressing dsRNA of Bdecr and Bdrpl19 with artificial diet to maggots of $B$. dorsalis resulting in severe defects in terms of developmental changes. Subsequently, mortality of maggots, emerged pupae and adults of $B$. dorsalis, along with suppression of these target genes expression in emerged adults showing potential of RNAi for control of $B$. dorsalis.

\section{Material and methods \\ Collection, rearing, and maintenance of Bactrocera dorsalis}

Fruit fly (B. dorsalis) that infested guava fruits (showing typical symptoms of depression/egg punctures) were collected manually from College Orchard/Fruit Research Farm located at PAU, Ludhiana during July-September (2018-2019) (Fig. 1a-c). The eggs on the day of collection of infested fruits from the orchard were considered as 0-day old. Rearing of fruit flies was conducted at room temperature in Fruit Entomology Laboratory, Department of Fruit Science, PAU, Ludhiana. The collected infested guava fruits were kept in a glass jar containing autoclaved sand at the bottom (Fig. 1d). These infested fruits were rotten within 2 days, and maggots (Fig. 1e) separated from these (Fig. 1f) were reared on $30 \mathrm{ml}$ artificial semi-solid diet consisting of $4 \%$ yeast extract, $12 \%$ sucrose, $1 \%$ soya peptone, $0.1 \%$ sorbic acid, $0.6 \%$ 


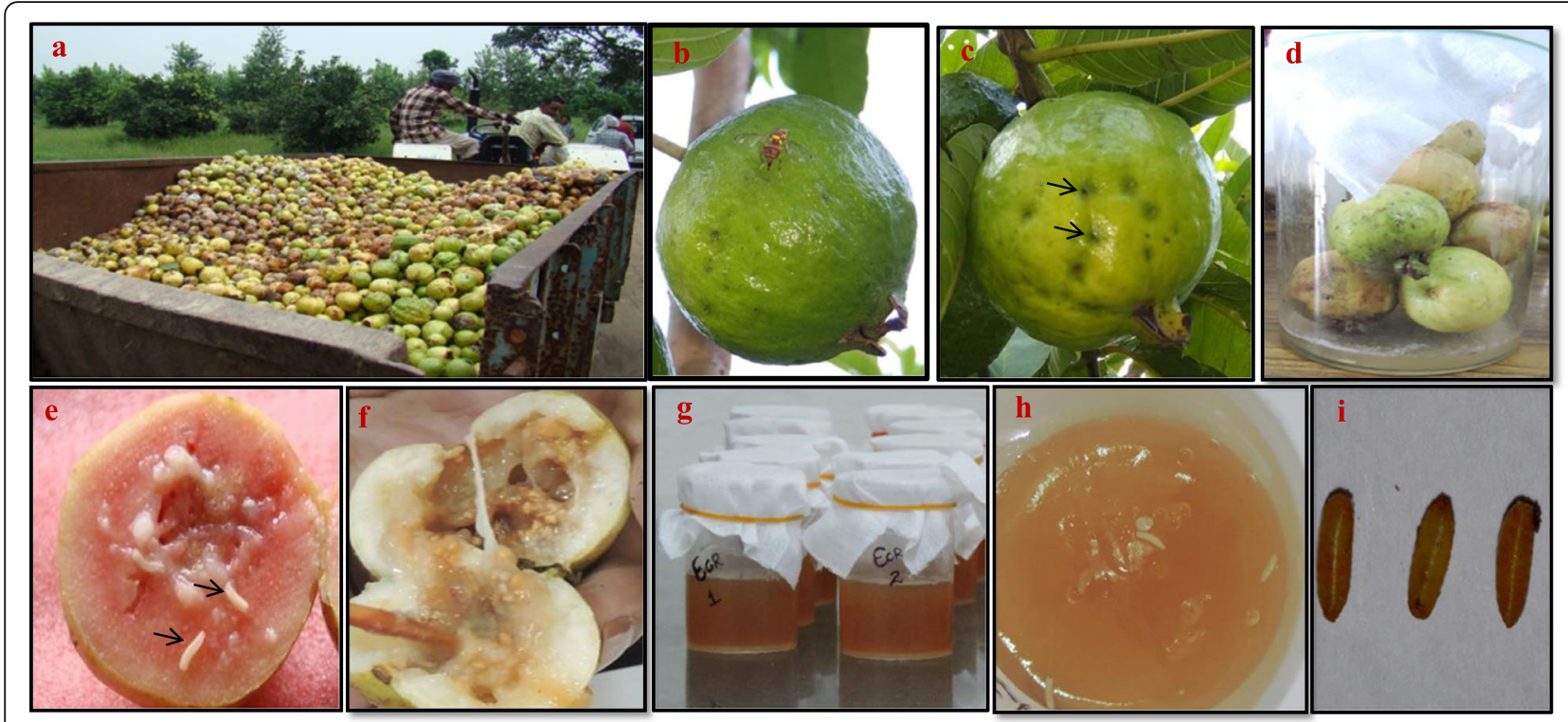

Fig. 1 Field view of guava orchard and fruit fly infested guava fruits collection at Punjab Agricultural University, Ludhiana (a), female fruit fly laying eggs on guava fruit (b), fruit fly-infested guava fruit on tree (c), fruit fly-infested guava fruits in glass jar (d), maggots of fruit fly developed from eggs in fruit (e), collection of maggots from infested guava fruits (f), rearing of maggots in artificial diet in laboratory ( $\mathbf{g})$, maggots feeding on artificial diet (h), pupae of fruit fly developed from maggot (i)

ascorbic acid, $1 \%$ agar, and $82 \%$ water in $50 \mathrm{ml}$ capacity glass vials covered with thin cloth for proper aeration (Fig. 1g, h). These maggots pupated (Fig. 1i) within 8-13 days at top of these vials or surface of the diet which were then collected and kept in a separate covered glass jar containing sugar, yeast autolysate, and water mixture as food supplement (Kamala Jayanthi and Verghese 2002) for newly emerged adult fruit flies. The adults were immediately shifted to cages of dimensions $45 \times 30$ $\times 30 \mathrm{~cm}$ containing sugar, yeast autolysate, and with a water-soaked cotton swab which were used to replace regularly to avoid microbial contamination. These newly emerged adult fruit flies within 6-12 days from these pupae were maintained in the laboratory at $28{ }^{\circ} \mathrm{C} \pm 2$ at 12-h light:12-h dark photoperiod. Fresh guava fruits without any infestation were also placed in cages for egg collection. The eggs were successfully laid by the sexually mature mated $B$. dorsalis female on these guava fruits. The rotten fruits were removed from cages to avoid any microbial contamination. These fruit flies used under study were maintained in the laboratory for two generations before using it for experiments. The maggots hatched from eggs were reared on same artificial diet in laboratory and were used for bacteria expressing dsRNA feeding experiment.

\section{RNA isolation, CDNA synthesis, and amplification of $B$. dorsalis-specific genes fragments}

Total RNA was isolated from 20 adult B. dorsalis collected from guava fruits by using Trizol reagent
(Invitrogen) following manufacturer's instructions. Two micrograms of total RNA was used, and cDNA was synthesized using 200 U SuperScript III Reverse Transcriptase (Invitrogen, USA), Oligod $\mathrm{T}_{12-18 \text { nucleotide }}$ primer (Invitrogen), $10 \mathrm{mM}$ dNTPs mixture, and 0.1 M DTT. Gene-specific primers were designed based on available $E C R$ and RPL19 gene sequences of B. dorsalis at NCBI to amplify $355 \mathrm{bp}$ and $692 \mathrm{bp}$ regions of ECR and RPL19 genes containing their important conserved domains. The cDNA synthesis was confirmed by PCR amplification with actin gene-specific primers (as internal control) Bdactin PF 5'-ATCTGGCATCACACTTTCTAC-3' and Bdactin PR 5'-GTCATCTTCTCACGGTTAGC-3'. PCR conditions were $94{ }^{\circ} \mathrm{C}$ for $4 \mathrm{~min}$ for the initial cycle, 94 ${ }^{\circ} \mathrm{C}$ for $30 \mathrm{~s}, 53{ }^{\circ} \mathrm{C}$ for $30 \mathrm{~s}, 72{ }^{\circ} \mathrm{C}$ for $30 \mathrm{~s}$ was repeated for the following 25 cycles, and final amplification at 72 ${ }^{\circ} \mathrm{C}$ for $7 \mathrm{~min}$. Using equal amount of cDNA prepared as template, reverse transcription-PCR was attempted using $E C R$ and RPL19 genes-specific primers. The PCR reaction of $25 \mu \mathrm{l}$ contained two microliter cDNA as template, $2.5 \mu \mathrm{l}$ of $10 \times \mathrm{Taq}$ buffer, $0.5 \mu \mathrm{l}$ each of forward and reverse primers $(10 \mu \mathrm{M}), 0.5 \mu \mathrm{l}$ of $10 \mathrm{mM}$ dNTPs mixture and $1 \mathrm{U}$ of Taq DNA polymerase (Qiagen, Germany). Primers BdEcr PF 5'-GGCGGTCATA TACAAACTGATCTG-3' and BdEcr PR 5-'CGTCCCAGATTTCTTCGAGG-3' were used for ecr gene amplification while Bdrpl19 PF 5'-GGACCCTAATGAAA TCAACGA-3' and Bdrpl19 PR 5'-GGATGTATTC CATTAAGACACG-3' were used for rpl19 gene amplification. The PCR conditions were kept as $94{ }^{\circ} \mathrm{C}$ for 4 
min for the initial cycle, $94{ }^{\circ} \mathrm{C}$ for $30 \mathrm{~s}, 54{ }^{\circ} \mathrm{C}$ (for $E C R$ ) or $52{ }^{\circ} \mathrm{C}$ (for $R P L 19$ ) for $30 \mathrm{~s}, 72{ }^{\circ} \mathrm{C}$ for $45 \mathrm{~s}$ which were repeated for the following 25 cycles, and final amplification at $72{ }^{\circ} \mathrm{C}$ for $7 \mathrm{~min}$. The PCR products were resolved on $1.5 \%$ agarose gel and electrophoresis was done for 1 $\mathrm{h}$ at $90 \mathrm{~V}$, and photographed under a gel documentation system. The desired $355 \mathrm{bp}$ and $692 \mathrm{bp} \mathrm{ECR} \mathrm{and} \mathrm{RPL19}$ genes-specific fragments were amplified which were confirmed through sequencing (Eurofins scientific).

\section{ECR and RPL19 transcript expression}

In order to investigate the endogenous transcript expression of ECR and RPL19 genes in maggot and adult stages of $B$. dorsalis, the present experiment was conducted. Total RNA was isolated from third instar maggots and newly emerged adult fruit flies. Two micrograms of total RNA from each of the samples were used and cDNA was synthesized as described above. An equal quantity of cDNA from each of the samples was used for RT-PCR analysis. RT-PCR was carried out using genes-specific primer sets as described earlier. Optimal amplification of $B d E C R$ and BdRPL19 transcript was standardized at exponential phase in PCR. The PCR amplified product was separated on $1.5 \%$ agarose gel, and the relative level of these genes transcript expression was estimated densitometrically using gel documentation system (Ultra-Violet Products Ltd.).

\section{RNAi feeding vector construction and production of dsRNA}

Specific partial regions of these genes were amplified through PCR for designing dsRNA which is the trigger of RNAi. Since the conserved domains are important for gene expression and thus amplifying this region for making RNAi cassette will enhance the gene silencing efficiency (Mohanpuria et al. 2011). Cloning of each of the candidate gene fragments into pL4440 (RNAi feeding vector) for making dsRNA expression vector is the preliminary step in the production of corresponding dsRNA. After obtaining the sequence information restriction maps for each of the two fruit fly gene sequences were prepared using NEBcutter V 2.0 (http://nc2.neb.com/NEBcutter2/). The vector pL4440 possesses multiple cloning sites between the two T7 RNA promoters placed in inverse direction. The ECR (692bp) and RPL19 (355bp) genes fragments were first cloned separately in pGEMT-easy vector plasmid and after restrict digestion; they were cloned in pL4440 vector at $B g l \mathrm{II}$ and XhoI restriction sites respectively. When a gene sequence is cloned between these T7 promotors, two RNAs of complementary strands are produced upon IPTG induction at $37{ }^{\circ} \mathrm{C}$. Each of the recombinant vectors L4440-ECR and L4440-RPL19 were then transformed into competent cells of RNaseIII deficient E. coli strain HT115 (DE3) to prevent degradation of dsRNA produced upon IPTG induction. This strain of E. coli has an inducible gene that codes for T7 RNA polymerase which uses the $\mathrm{T} 7$ promoters located in the vector to transcribe RNA from both strands of the insert. The bacterial colonies were confirmed through colony PCR and restriction digestion of recombinant pL4440. Single colony of HT115 (DE3) bacteria harboring these plasmids were cultured in LB media at $37{ }^{\circ} \mathrm{C}$ with shaking $(220 \mathrm{rpm})$ under antibiotic selection (100 $\mathrm{\mu g} / \mathrm{ml}$ ampicillin) overnight. The culture was diluted 100 -fold, i.e., from the bacterial primary culture, secondary culture was prepared with 1:100 concentration, in $2 \mathrm{l} \mathrm{LB}$ with $100 \mu \mathrm{g} / \mathrm{ml}$ ampicillin cultured at $37{ }^{\circ} \mathrm{C}$ and allowed to grow to optical density $600=$ 0.4 to 0.6 to standardize the maximum dsRNA production. Usually, 0.4 O.D. of secondary culture has been considered optimum for IPTG induction (Li et al. 2011). IPTG induction was also standardized at different time periods like 2, 2.30, 3, 3.30, and $4 \mathrm{~h}$. Synthesis of T7 polymerase was induced by adding with $0.4 \mathrm{mM}$ IPTG, and the bacteria were incubated with shaking for an additional $4 \mathrm{~h}$ at $37{ }^{\circ} \mathrm{C}$. The dsRNA of ECR and RPL19 gene fragments were extracted from transformed bacteria using Trizol reagent (Invitrogen), and their desired length was confirmed by electrophoresis on $1.5 \%$ agarose gel. For bacteria feeding experiment, bacteria culture was centrifuged at $4000 \times g$ for $5 \mathrm{~min}$, and the pellet was resuspended in $8 \mathrm{ml}$ sterile water to condense the concentration to $200 \times$.

\section{DsRNA containing bacteria feeding bioassay}

For maggot feeding experiments, the bacteria expressing dsRNA of these two candidate genes were mixed individually with $30 \mathrm{ml}$ of same semi-solid artificial diet (containing ampicillin and tetracycline) at different concentration at $200 \mu \mathrm{l}$ of $200 \times\left(1 \times 10^{8}\right.$ cells $), 350 \mu \mathrm{l}$ of $200 \times\left(1.75 \times 10^{8}\right.$ cells $)$, and $700 \mu \mathrm{l}$ of $200 \times\left(3.5 \times 10^{8}\right.$ cells) and was kept in a 50-ml capacity glass vial covered with a thin cloth to allow aeration. Newly emerged 100 maggots of $B$. dorsalis were used for the treatment for each concentration of bacteria expressing dsRNA of target genes. The control group was fed with artificial diet with the highest amount $(700 \mu \mathrm{l})$ of bacteria expressing empty pL4440 plasmid without any gene fragment. This common control treatment was there to compare with both ecr and rpl19 treatments. The artificial diet was fed continuously up to 15 days, and diet was renewed at every fifth day from first day of feeding to provide a continuous supply of dsRNA to maggots. The experiment was performed in three replications and during two consecutive years (2018-2019) to compare the efficiency. 
Evaluation of bacteria expressing dsRNA-mediated gene silencing on growth and development of different stages of $B$. dorsalis

Different parameters like growth, development, mortality, and survival rates of all treated maggots of $B$. dorsalis were recorded up to adult fruit fly formation. Also, different phenotypic abnormalities in different developmental stages were also photographed.

\section{Statistical analysis}

The data was analysed using GraphPad prism 8.0 (GraphPad Software, San Diego, USA) software. Independent $t$ test was used to compare the relative expression of genes during maggot and adult stages of fruit fly and percent mortality between the two RNAi feeding experiment. One-way ANOVA followed by Tukey's multiple comparison as post hoc test was used to compare mortality rate between maggots, pupae and adults of different RNAi feeding experiments. The RNAi feeding experiments were prepared for two consecutive years (2018-2019) each with 3 replications. For all tests $p<$ 0.05 was considered significant.

\section{Results and discussion}

Two vital genes, ECR and RPL19 of B. dorsalis, namely were selected and their potential role in normal growth, development, and metamorphosis in different developmental stages of $B$. dorsalis were accomplished by ingestion from bacterial expressed corresponding dsRNA. To reduce the cost of production, increase the stability of dsRNA, and for ease of treatments to the maggot, bacteria expressing dsRNA was used instead of dsRNA extract. Remarkably, we found that dsRNA-mediated gene silencing effect through oral administration of bacteria was persistent and effective as demonstrated by reduced survival of maggots, pupae, and adult fruit flies and deformities phenotypically observed especially in pupae and adults stages.

\section{Amplification of candidate genes fragments and sequence submission}

Based on NCBI database search, different available sequences of ECR (JX105044.1, JQ034623.1) and RPL19 (HQ315780.1, KJ028105.1) genes of B. dorsalis were retrieved, and their conserved domain search was attempted to design the specific primers. The 692bp $E C R$ and 355bp RPL19 genes fragments were amplified using gene-specific primer sets (Fig. 2a, b). This partial cDNA sequence of $E C R$ shared $99 \%$ identity in sequence alignment with $B$. dorsalis, $94 \%$ sequence identity to $\mathrm{Cer}$ atitis capitata, $85 \%$ identity to Calliphora vicina, and $84 \%$ identity to Lucilia cuprina. The partial cDNA

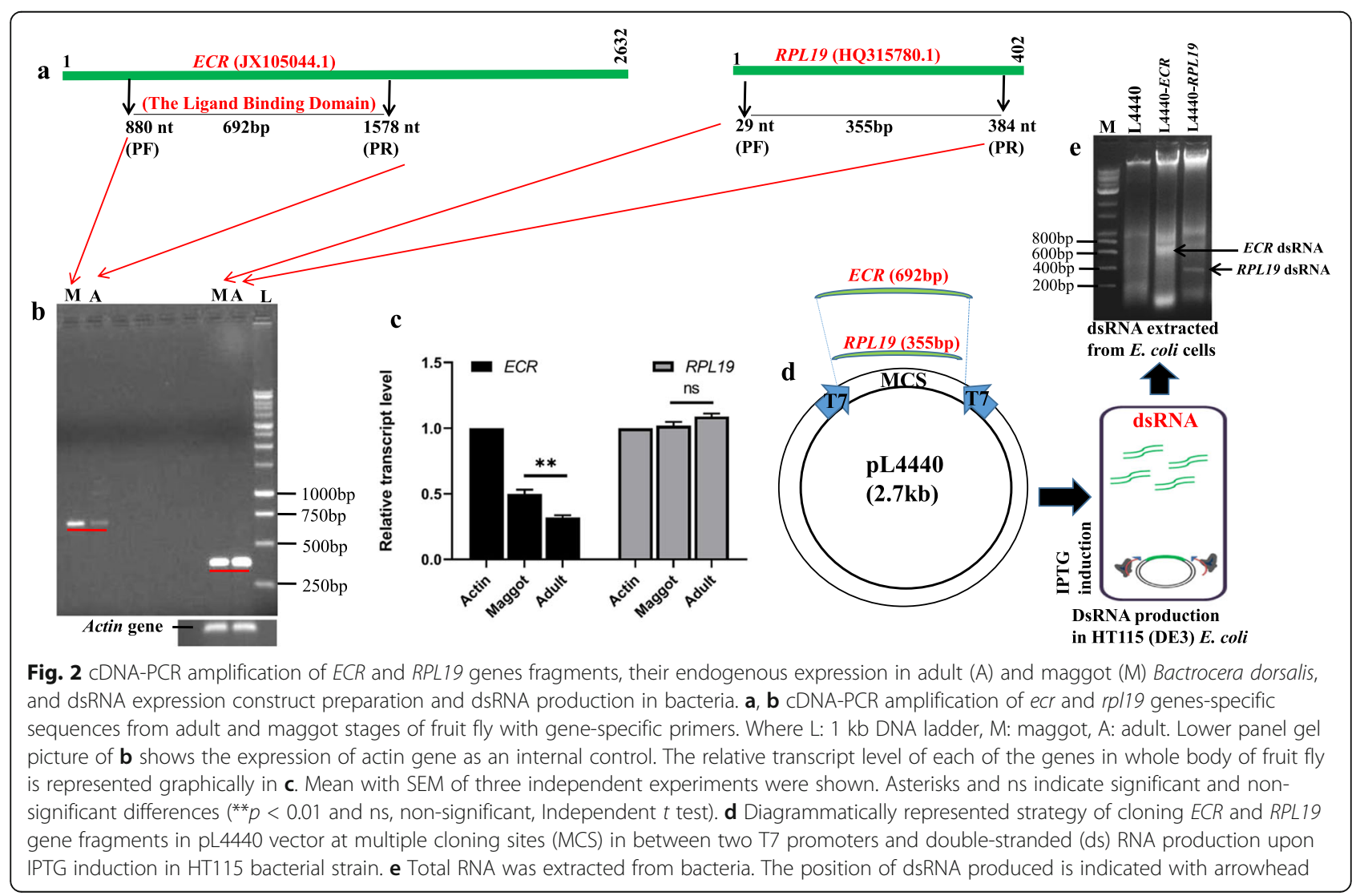


sequence of RPL19 shared $97 \%$ identity to B. dorsalis and $93 \%$ identity to $B$. minax. These isolated $E C R$ and RPL19 gene fragments sequences were submitted on GenBank with the accession number MN311494.1 and MN311495.1, respectively.

\section{Endogenous expression of ECR and RPL19 genes of $B$. dorsalis in maggot and adult stages}

Total RNA was isolated from maggot and adult $B$. dorsalis reared on guava fruits and CDNA was synthesized using its equal concentration. Actin gene-specific amplification was chosen as an internal control because of its stability in expression during all the insect stages and its expression is less likely to be affected by environmental condition (Shen et al. 2010). Endogenous transcript expression of target gene is always important before attempting RNAi studies. To investigate the endogenous transcript expression of ecr and rpl19 genes in maggot as well as adult stages of $B$. dorsalis, equal amount of cDNA as template was used in reverse transcriptionPCR using genes-specific primers. The transcript expression of ecr was higher in maggot as compared to adult fruit fly stage (Fig. 2b, c). On the other hand, transcript expression of rpl19 was nearly the same in both maggot and adult stages of fruit fly (Fig. 2b, c). Further, relative transcript expression of $r p l 19$ was much higher than that of ecr gene (Fig. 2b, c).

\section{Effects of feeding bacteria expressing dsRNA of Bdecr on $B$. dorsalis mortality and its $E C R$ gene expression}

In order to express dsRNA, ECR gene fragment was cloned in pL4440 RNAi feeding vector plasmid. Upon induction in IPTG, corresponding dsRNA was produced in HT115 (DE3) bacterial strain harboring pL4440-ECR construct (Fig. 2d). Bacteria expressing dsRNA-ecr feeding to maggots of $B$. dorsalis experiment was attempted in 2 consecutive years (2018-19). In both years, the mortality/deformity rate of maggots, pupae, and adult emerged were increased with the increase in concentration of bacteria expressing dsRNA of Bdecr in artificial diet. Seven hundred microlitre concentration of bacteria produced highest mortality and deformities as compared to that of $350 \mu \mathrm{l}$ and $200 \mu \mathrm{l}$ of bacterial concentration (Fig. 3a). In $700 \mu \mathrm{l}$ bacterial treatment, $56.7 \%$ mortality of maggots along with deformities in pupal and adult stages within 15 days of start of feeding (Fig. 3) were observed, followed by 32.9 and $16.7 \%$ in $350 \mu \mathrm{l}$ and $200 \mu \mathrm{l}$, respectively, on an average data of the 2 years experiments. Of the pupae developed from survived treated maggots, $51,24.9$, and $14 \%$ mortality was observed in 700,350 , and $200 \mu \mathrm{l}$ bacterial treatments respectively in the 2 consecutive years. Of the emerged adults from survived pupae, mortality of $35.3,19$, and $10.5 \%$ were observed in 700,350 , and $200 \mu \mathrm{l}$ bacterial treatments respectively in the 2 consecutive years (Fig. 3, Supplementary data Table 1). Finally very few adult fruit flies were survived at the end. On comparing 2 years data, the mortality of maggots, pupae, and adults was higher in 2018 than in 2019. Thus, total mortality/deformity of maggots, pupae, and adult fruit flies was $86.3 \%$ in 2018 2019 and was highest in $700 \mu \mathrm{l}$ bacterial treatment compared to 55 and $35.8 \%$ in 350 and $200 \mu \mathrm{l}$ dsRNAs Bdecr bacterial treatments, respectively (Supplementary data Table 1).

Thus, it appears that ecr-dsRNA was more effective to trigger RNAi silencing at early developmental stages of fruit fly. Present results were consistent with the observed RNAi silencing effect as in Nilaparveta lugens, where feeding of dsRNA targeting ecr and usp genes to nymphs resulted in disruption of molting and reduced the survival of nymphs (Yu et al. 2014). Earlier, RNAi targeting ecr and usp genes injected into larvae of Bombyx mori resulted in $40 \%$ pre-pupal death and failure to undergo larval-pupal metamorphosis and stopped at larval-pupal intermediates. Feeding of ecr-dsRNA through artificial diet to second instar grain aphids (Sitobion avenae) resulted in 50\% aphid mortality after 4 days of treatment (Yan et al. 2016). The role of ecr is significantly important during the immature stages and its endogenous expression was higher in maggot stage than in adult stage of $B$. dorsalis. And maggots showed significant and higher mortality and deformity upon ingestion of desired dsRNA, which was a proof of high gene silencing efficiency (Fig. $3 \mathrm{a}-\mathrm{c}$ ). Since the requirement of rpl19 gene product is very common and important during all growth developmental stages of every insect pest and thus, required throughout the life cycle. Thus, obviously the endogenous expression of rpl19 was nearly same in both maggot and adult stages. Therefore, both maggot and adult stages of $B$. dorsalis showed significant mortality and deformity (Fig. 3a-c).

Gene silencing in terms of reduced relative transcript level of endogenous $B d E C R$ gene was also observed after 15 days of feeding bacteria $(700 \mu \mathrm{l})$ expressing dsRNA$E C R$ in treated third instar maggots and subsequent emerged adult fruit flies which was reduced by 33 and $23 \%$, respectively, than the native $E C R$ gene expression in B. dorsalis (Fig. 3c).

\section{Effects of feeding bacteria expressing dsRNAs of Bdrpl19 on $B$. dorsalis mortality and its RPL19 gene expression}

In order to express dsRNA, RPL19 gene fragment was also cloned in pL4440 RNAi feeding vector plasmid. Upon induction in IPTG, corresponding dsRNA was produced in HT115 (DE3) bacterial strain harboring pL4440-RPL19 construct (Fig. 2d). Bacteria expressing dsRNA-rpl19 feeding to maggots of $B$. dorsalis experiment was also attempted in the 2 consecutive years 

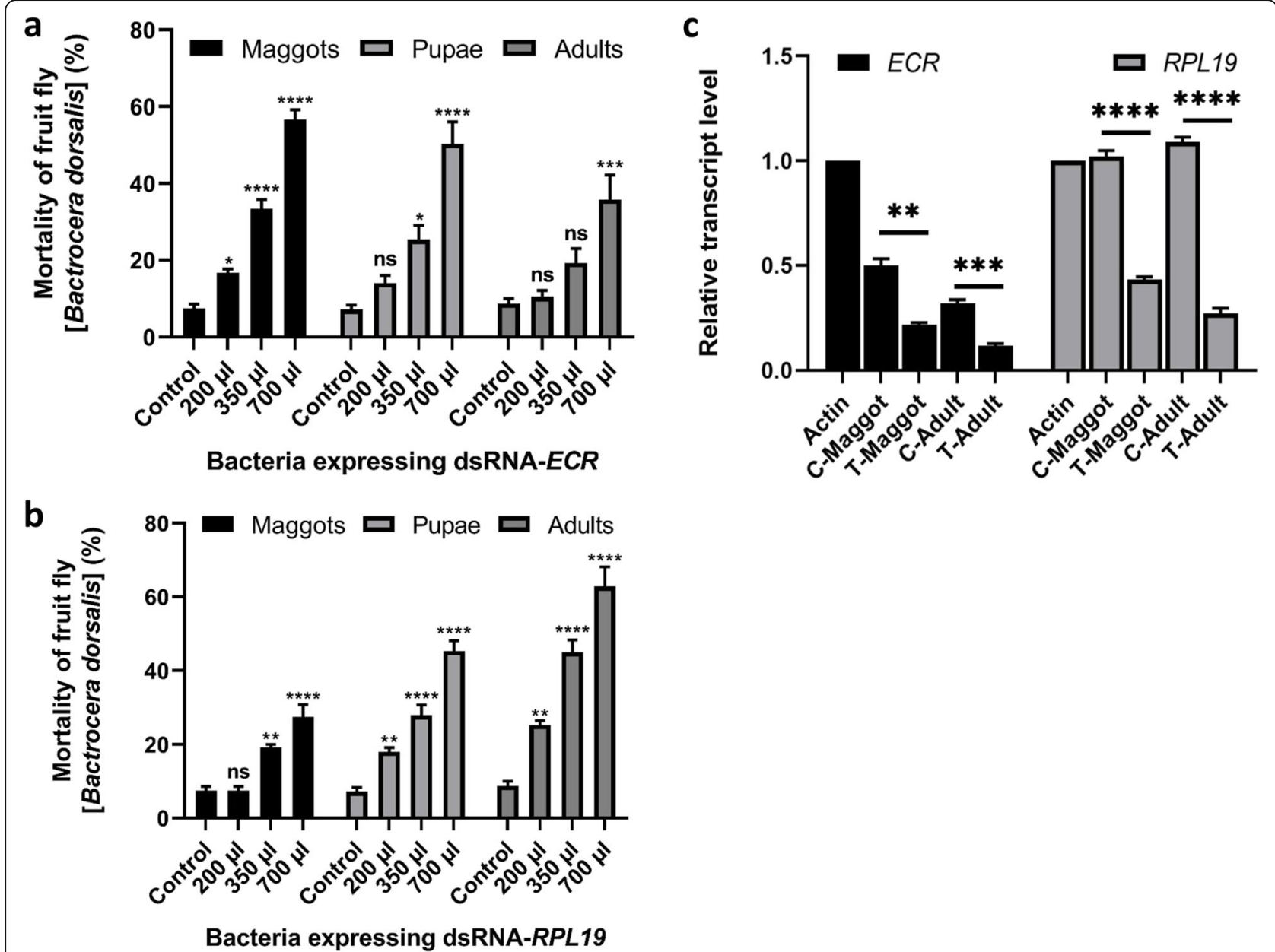

Fig. 3 Effects of feeding bacteria expressing dsRNA-ECR (a) and dsRNA-RPL19 (b) on fruit fly (Bactrocera dorsalis). Mortality of maggots, pupae, and adult fruit flies were monitored after feeding artificial diet containing bacteria at different concentration at $200 \mu \mathrm{l}$ of $200 \times\left(1 \times 10^{8}\right.$ cells), $350 \mu \mathrm{l}$ of $200 \times\left(1.75 \times 10^{8}\right.$ cells), and $700 \mu \mathrm{l}$ of $200 \times\left(3.5 \times 10^{8}\right.$ cells $)$ expressing dsRNA-ECR and dsRNA-RPL 19 to maggots and data were collected up to 15 days of feeding. The control group was fed with artificial diet with the highest amount (700 $\mu$ l) of bacteria expressing pL4440 plasmid without any gene fragment. Mean with SEM of six replications were shown for the 2 years data (2018-2019). Asterisks and ns indicates significant and non-significant differences $\left({ }^{*} p<0.05,{ }^{* *} p<0.001,{ }^{* * *} p<0.0001\right.$ and $n s$, non-significant, ANOVA followed by Tukey's multiple comparison as post hoc test). c Suppression of target genes, ECR and RPL19 in whole maggot and adult fruit fly after 15 days of feeding bacteria (700 $\mu$ l) expressing dsRNA-ECR and dsRNA-RPL19 to maggots. Ten maggots were homogenized to obtain one RNA sample and expression was quantified with RT-qPCR and normalized against housekeeping gene actin. Each data represents a biological replicates

(2018-2019). In both years, the mortality (including deformity) rate was increased with increase in concentration of bacteria expressing dsRNA as was in case of ecr. Seven hundred microliter concentration of bacteria produced higher mortality and deformities as compared to that of $350 \mu \mathrm{l}$ and $200 \mu \mathrm{l}$ (Fig. 3b, Supplementary data Table 2). In $700 \mu$ l treatment, $27.9 \%$ mortality of maggots was observed, followed by 19.2 and $7.5 \%$ in 350 and $200 \mu \mathrm{l}$, respectively, on an average data of the 2 years (2018-2019) experiments. Of the pupae developed, 45.5, 27.8 , and $18.5 \%$ mortality was observed in 700,350 , and $200 \mu \mathrm{l}$ treatments, respectively, and of the emerged adults, mortality of $69.8 \%$ (along with deformities in maggot and pupal stages) (Fig. 3), 44.3, and 26\% was observed in 700, 350, and $200 \mu$ l treatments, respectively in 2018-2019. On comparing the 2 years data, the mortality rate of maggots and adults was little higher in 2019 than in 2018. Thus, on an average, total mortality/deformity of maggots, pupae, and adult fruit flies was $87.9 \%$ in $2018-2019$ and was highest in $700 \mu \mathrm{l}$ dsRNAs of Bdrpl19 bacterial treatment compared to 67.5 and $44.2 \%$ in 350 and $200 \mu \mathrm{l}$ bacterial treatments, respectively (Supplementary data Table 2). Feeding of bacteria expressing rpl19-dsRNA at $700 \mu \mathrm{l}$ dose to maggots resulted in high adult mortality (69.8\%) along with deformities in maggot and pupal stages (Fig. 3). Thus, it appears that rpl19-dsRNA is more effective to trigger RNAi silencing at adult stage of fruit fly. In contrast, 
despite to provide continuous supply of bacteria expressing dsRNA of either ECR or RPL19 gene for feeding to Bactrocera maggots did not result in overexpression of these target genes by formation of RNAi refractoriness as observed by Li et al. (2011) rather produced higher gene knock down affecting growth and development of Bactrocera adversely to survive very less fruit flies (13.1\%) at last.

Gene silencing in terms of reduced relative transcript level of endogenous BdRPL19 gene was also observed after 15 days of feeding bacteria $(700 \mu \mathrm{l})$ expressing dsRNA-RPL19 in treated 3rd instar maggots and subsequent emerged adult fruit flies which was reduced by 62 and $84 \%$, respectively, than the native RPL19 gene expression in B. dorsalis (Fig. 3c).

\section{Retarded development and abnormal phenotypes in different developmental stages of fruit fly}

The feeding of bacteria expressing dsRNA of ecr and rpl19 individually to maggots of $B$. dorsalis produced similar marked physiological deformities. In the present study, typical phenotypic abnormalities such as absence of wings, underdeveloped abdomen and absence of legs, absence of complete abdomen, adults with severely curled wings and/or shrinked abdomen, malformed legs, and incomplete eclosion were observed in emerged adult $B$. dorsalis upon feeding E. coli expressing ecr-dsRNA or
rpl19-dsRNA. It is very fascinating that similar types of phenotypic malformations have been observed earlier by treatment of Bactrocera with insecticides belonging to different chemical groups like Beticol, Biosad, Elsan, Lufox, Mani, Match, and Radiant. The tested insecticides reduced the fecundity and hatchability percentage and also caused high levels of sterility for adult females emerged from treated pupae (Halawa et al. 2013). Earlier, precocious lethal molt and several growth inhibitory effects were also observed by ingestion of tebufenozide by white tussock moth larvae and spruce budworm larvae (Dhandialla et al. 2005). Further, ECR is the target of bisacylhydrazine insecticides used against several pests (Billas and Moras 2005). The finding indicates the feasibility of orally delivered dsRNA method and silencing of these 2 potential genes of $B$. dorsalis to produce a proof of concept of RNAi gene silencing in fruit fly in laboratory conditions.

The maggot development, especially in dsRNA-ecr, was significantly affected and maggots produced were having change in melanization (gradual blackening on whole surface) and were reduced in size in comparison to control, and died prematurely. The maggots which survived were developed into puparium but produced change in melanization (black colored puparium) in contrast to normal pupae which are generally of tan or dark brown colored (Fig. 4a). Later on, the pupae which

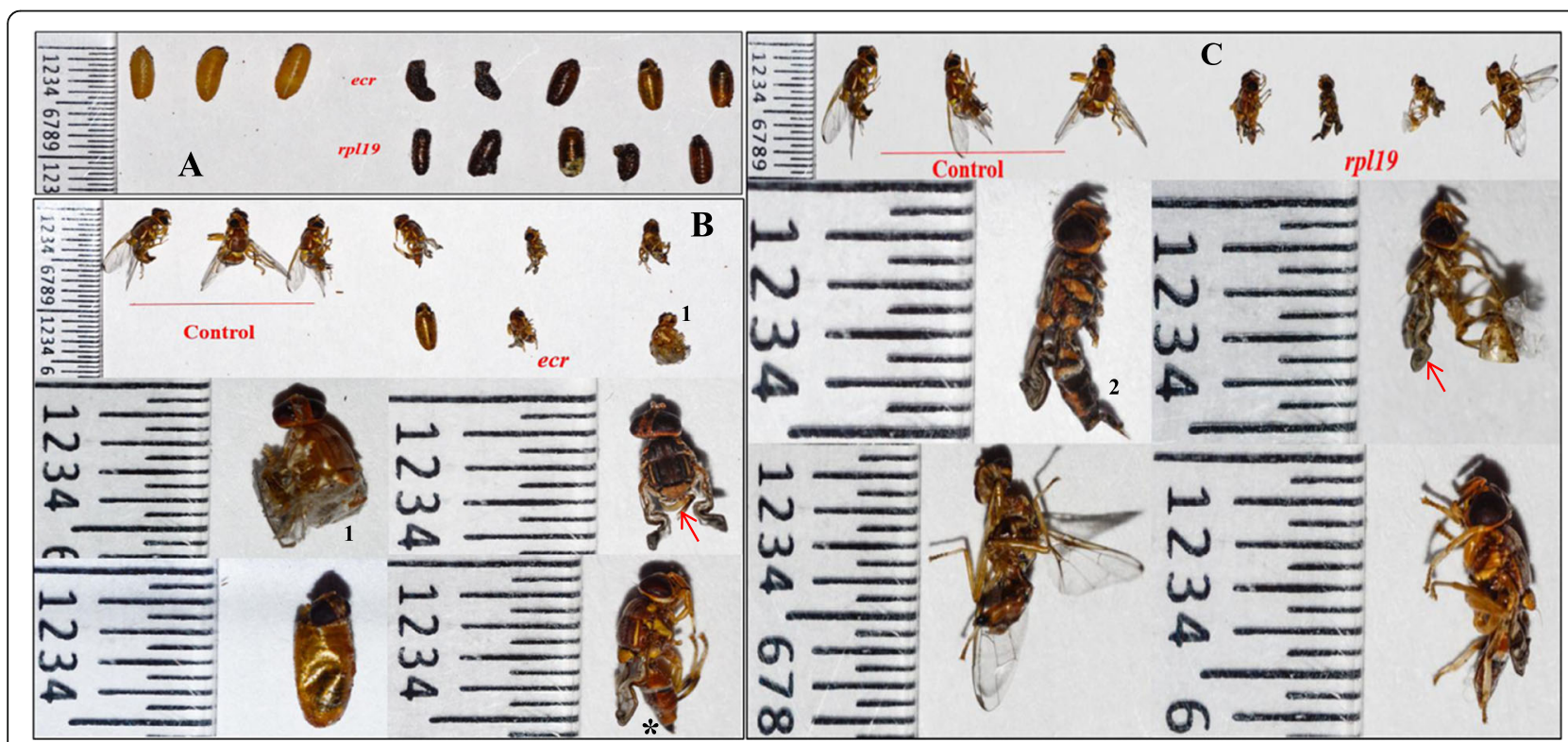

Fig. 4 Retarded development and abnormal phenotypes observed in pupal (a) and adult (b, c) fruit fly developmental stages upon feeding bacteria expressing dsRNA of ECR and RPL19 genes to maggots. Different abnormal phenotypes such as change in melanization (gradual blackening on whole surface) and reduction in size of pupae (a) were observed in comparison to control. The pupae which survived were converted into adult fruit flies but majority of them showed shrunk appearance and having underdeveloped body parts such as absence of wings, underdeveloped abdomen (indicated by arrow head) and absence of legs (2), and in some cases complete abdomen was absent (1), adults with severely curled wings and/or shrinked abdomen (indicated by *), malformed legs and even malformed adults and incomplete eclosion (b, c) were observed 
survived were converted into adult fruit flies but they showed shrunk appearance and underdevelopment, i.e., having underdeveloped body parts such as absence of wings and malformed legs, severely curled wings, underdeveloped abdomen and absence of legs, and in some cases complete abdomen was absent in comparison with control adult fruit flies which were normal in appearance (Fig. 4b). In case of control, normal maggot to pupa and pupa to adult developments were observed.

\section{Mechanism of dsRNA-based gene silencing in $B$. dorsalis}

A very high total mortality rate (including deformity) was observed in all the developmental stages of $B$. dorsalis, which has not been reported so far. It is well proven that plant incorporated dsRNA corresponding to an insect pest gene will have targeted activity against a particular insect pest as reported in western corn root worm (Bachman et al. 2016). The total average mortality (including deformity) in maggots, pupae, and adult $B$. dorsalis was little higher $(87.9 \%)$ in maximum concentration $(700 \mu \mathrm{l})$ of $B d r p l 19-\mathrm{dsRNA}$ bacterial treatment as compared than $86.3 \%$ in Bdecr-dsRNA bacterial treatment during the 2 consecutive years due to "loss of RNAi functions" phenotype (Saleh et al. 2006) and that ultimately resulted in death of flies. Based on earlier and present studies, it proves that oral administration of engineered HT115 bacterial strain is very much efficient to inhibit the target gene function in non-cell autonomous RNAi mode by transferring dsRNA without its degradation in insect body (Huvenne and Smagghe 2010). In the present study, RNAi effects of feeding bacteria expressing dsRNA within 15 days of start of feeding experiment was comparable as reported earlier by $\mathrm{Li}$ et al. (2011). But different typical phenotypic deformities observed in pupae and adult stages of $B$. dorsalis in our laboratory were not reported so far which validates the feasibility of this dsRNA expressing bacteria feeding method as more natural way of transferring intact dsRNA into insect body. As far as the roles of ECR and RPL19 genes are concerned, it was very obvious that RNAi effects produced due to silencing of these genes in whole body of $B$. dorsalis while not in particular tissues, despite to the uptake of corresponding dsRNA happens to be in midgut (Christiaens et al. 2020). In fact, different RNAi mechanisms of spreading the RNAi effector molecules could be possible in dipteran species; it can hypothesized that either dsRNA molecules along with artificial diet could be absorbed through the columnar cells having microvilli providing a large absorptive area with many channels and receptor-mediated endocytosis pathways (Joga et al. 2016) and after processing into siRNA molecules which actually moves to all other tissues and cells of $B$. dorsalis producing the silencing effects which ultimately resulted in phenotypic deformities in $B$. dorsalis. It was also very interesting that the sequence-specific dsRNA mediated silencing effects in terms of typical phenotypes were there from one developmental stage to another (Fig. 4).

Although, gene silencing effects were earlier reported in few studies, where feeding of bacteria expressing dsRNA to $B$. dorsalis adult targeting spermatogenesis reduced the number and length of spermatozoa stored in female spermathecal and significantly reduced the offspring hatching rate which further resulted in lesser number of maggots raised in fruits compared to control treatment (Dong et al. 2016). Similarly, feeding of dsRNA to $B$. dorsalis adults through artificial diet targeting spr resulted in 52\% silencing in fruit flies and the mean life span reduced to 31 days in treated fruit flies (Zheng et al. 2015). Feeding of bacterially expressed dsRNA of four genes involved in ecdysteroidogenesis, i.e., $p t t h$, torso, spook, and $n m-g$, showed knock down of these genes in Chilo suppressalis resulted in abnormal phenotypes, retarded development, and high larval mortality compared to control (Zhu et al. 2016). Thus, oral ingestion of bacterially expressed dsRNA into the body of insect seems to be a simple and appropriate mode to investigate potential management scheme for several important pests like $B$. dorsalis as observed in our study also.

In contrast to recently reported strong RNAi phenotypes in B. tryoni by complexing dsRNA targeting melanin synthesis gene, yellow with liposomes within the adult insect's diet (Tayler et al. 2019), we hereby, report high gene-silencing effects in terms of strong RNAi phenotypes including typical deformities and very high mortality rates at maggot, pupae, and adult developmental stages of $B$. dorsalis just by ingestion of bacteria expressing dsRNA. This could be due to absence of either dsRNases in the gut or the transfer of intact dsRNA through feeding of $E$. coli expressing dsRNA of two nonmidgut target genes in $B$. dorsalis. After the lysis of engineered bacteria inside the gut, these dsRNA could have processed into siRNAs, which is capable enough to target complementary mRNA transcripts of ECR or RPL19 gene present in different parts of body of $B$. dorsalis far away from the site of ingestion. This is sure that mechanism exists for the spread of RNAi signals in $B$. dorsalis as reported earlier. In fruit fly, systemic RNAi and dsRNA update is taken place through an active receptormediated endocytosis (Saleh et al. 2006). DsRNA is taken from the environment and then silencing signals are transferred through vesicle-mediated intracellular trafficking (Saleh et al. 2006; Tomoyasu et al. 2008). The dsRNA uptake by epithelial cells of the midgut in insects is very much significant for RNAi response. After midgut cells absorb the dsRNA, the transfer of these signals to intracellular RNAi machinery is also of paramount 
importance. The dsRNA uptake follows endocytosis pathway thus, enables its transfer to the cytoplasm through the discharge from endosome (Varkouhi et al. 2011).

\section{Conclusions}

The study provides a proof of concept for feasibility of silencing two vital genes by feeding bacteria expressing dsRNA in different developmental stages of $B$. dorsalis and subsequently producing severe mortality and deformity in all developmental stages of fruit fly. In this context, we have prepared a marker-free ihpRNA construct (RNAi construct) using the same ECR gene of $B$. dorsalis and standardizing the in planta (floral dip) transformation of 'Allahabad safeda', a popular guava cultivar in India to mobilize our desired RNAi cassette and RNAi-based guava plants resistant to fruit fly could be realize in near future. In addition, spray-based formulations of dsRNA would be prepared by encapsulation of desired dsRNA in nanoparticles to increase the stability of dsRNA in field or spray of bacteria expressing these dsRNA of target genes of fruit fly would be utilized in future.

\section{Supplementary Information}

The online version contains supplementary material available at https://doi. org/10.1186/s41938-020-00345-7.

Additional file 1: Table 1. Effects of feeding bacteria expressing dsRNAecr to maggots of fruit fly, Bactrocera dorsalis during 2018 and 2019. *Mean and standard error of 6 replications (3 replications per year).

Additional file 2: Table 2. Effects of feeding bacteria expressing dsRNArp/19 to maggots of fruit fly, Bactrocera dorsalis during 2018 and 2019.

*Mean and standard error of 6 replications (3 replications per year).

\section{Abbreviations}

B. dosalis: Bactrocera dorsalis; E. coli: Escherichia coli; dsRNA: Double-stranded RNA; ecr: Ecdysone receptor; rp/19: Ribosomal protein L19; Bdecr: Bactrocera dorsalis ecdysone receptor; Bdrp/19: Bactrocera dorsalis ribosomal protein L19; B. correcta: Bactrocera correcta; IPM: Integrated Pest Management; RNAi: RNA interference; spr: Sex peptide receptor; USP: Ultraspiracle protein; PCR: Polymerase chain reaction; IPTG: Isopropyl $\beta$-D thiogalactopyranoside; LB: Luria Broth; siRNA: Small interfering RNA

\section{Acknowledgements}

The authors are thankful to the University, for providing the internal grant to carry out the present research work. Bacteria HT115 strain was kindly provided by the Caenorhabditis Genetics Centre (CGC), University of Minnesota, USA, which is funded by National Institutes of Health (NIH) Office of Research Infrastructure Programs (P40 OD010440) is duly acknowledged. Authors are thankful to Dr. Dominique Rasoloson, Research Specialist, Department of Molecular Biology \& Genetics, Johns Hopkins University School of Medicine, USA, and Professor K. Subramaniam, Department of Biotechnology, Indian Institute Technology, Madras, for providing pL4440 plasmid and technical assistance in plasmid preparation.

\section{Authors' contributions}

For the preparation of present manuscript, MG did attempted all experiments; SS provided material support and technical support; SK attempted some part of experiment; PM and GSS designed the experiments and edited the manuscript; and PC provided the critical suggestions and reviewed the experiments. All authors read and approved the final manuscript.

\section{Funding}

This research was supported with internal grant from Punjab Agricultural University, Ludhiana, and did not receive any specific grant from funding agencies.

\section{Availability of data and materials}

Not applicable

\section{Ethics approval and consent to participate}

Not applicable

\section{Consent for publication}

Not applicable

\section{Competing interests}

The authors declare no competing interests regarding the work published.

Received: 10 September 2020 Accepted: 30 November 2020

Published online: 01 January 2021

\section{References}

Allwood AJ, Chinajariyawong A, Drew RAl, Hamacek EL, Hancock DL, Hengsawad C, Jinapin J, Jirasurat M, Kong Krong C, Kritsaneepaiboon S, Leong CTS, Vijaysegaran S (1999) Host plant records for fruit flies (Diptera: Tephritidae) in South East Asia. Raffles Bull Zool 47(Supplement 7):1-92 http://era.daf.qld. gov.au/id/eprint/3584/

Bachman PM, Huizinga KM, Jensen PD, Mueller G, Tan J, Uffman JP, Levine SL (2016) Ecological risk assessment for DvSnf7 RNA: a plant-incorporated protectant with targeted activity against western corn rootworm. Regul Toxicol Pharmacol 81:77-88. https://doi.org/10.1016/j.yrtph.2016.08.001

Billas IM, Iwema T, Garnier JM, Mitschler A, Rochel N, Moras D (2003) Structural adaptability in the ligand-binding pocket of the ecdysone hormone receptor Nature 426:91-96. https://doi.org/10.1038/nature02112

Billas IM, Moras D (2005) Ligand-binding pocket of the ecdysone receptor. Vitam Horm 73:101-129. https://doi.org/10.1016/S0083-6729(05)73004-1

Christiaens O, Niu J, Nji Tizi Taning C (2020) RNAi in insects: a revolution in fundamental research and pest control applications. Insects 11(7):E415. https://doi.org/10.3390/insects11070415

Dhandialla TS, Retnakaran A, Smagghe G (2005) Insect growth and development disrupting insecticides. In: Gilbert LI, latrou K, Gill SS (eds) Comprehensive Insect Molecular Science, vol 6. Pergamon Press, Oxford, pp 55-100 http:// hdl.handle.net/1854/LU-342182

Dong YC, Wang ZJ, Chen ZZ, Clarke AR, Niu CY (2016) Bactrocera dorsalis male sterilization by targeted RNA interference of spermatogenesis: empowering sterile insect technique programs. Sci Rep 6:35750. https://doi.org/10.1038/ srep35750

Halawa SM, El-Hosary RAA, Mosallam AMZ, El-Khayat EF, Ismail MMS (2013) Toxicological, biological and biochemical effects of certain insecticides on Bactrocera zonata (Saunders) (Diptera, Tephritidae). Am Eurasian J Toxicol Sci 5:55-65. https://doi.org/10.5829/idosi.aejts.2013.5.3.1110

Huvenne H, Smagghe G (2010) Mechanisms of dsRNA uptake in insects and potential of RNAi for pest control: a review. J Insect Physiol 56:227-235. https://doi.org/10.1016/j.jinsphys.2009.10.004

Joga MR, Zotti MJ, Smagghe G, Christiaens O (2016) RNAi efficiency, systemic properties, and novel delivery methods for pest insect control: what we know so far. Front Physiol 7:553. https://doi.org/10.3389/fphys.2016.00553

Kamala Jayanthi PD, Verghese A (2002) A simple and cost-effective mass rearing technique for the tephritid fruit fly, Bactrocera dorsalis (Hendel). Curr Sci 82(3):266-268 https://www.jstor.org/stable/24106605

Li X, Dong X, Zou C, Zhang H (2015) Endocytic pathway mediates refractoriness of insect Bactrocera dorsalis to RNA interference. Sci Rep 5:8700. https://doi. org/10.1038/srep08700

Li X, Zhang M, Zhang H (2011) RNA interference of four genes in adult Bactrocera dorsalis by feeding their dsRNAs. PLoS One 6:e17788. https://doi org/10.1371/journal.pone.0017788

Mohanpuria P, Kumar V, Ahuja PS, Yadav SK (2011) Producing low-caffeine tea through post-transcriptional silencing of caffeine synthase mRNA. Plant Mol Biol 76(6):523-534. https://doi.org/10.1007/s11103-011-9785-x 
Saleh MC, van Rij RP, Hekele A, Gillis A, Foley E, O'Farrell PH, Andino R (2006) The endocytic pathway mediates cell entry of dsRNA to induce RNAi silencing. Nat Cell Biol 8:793-802. https://doi.org/10.1038/ncb1439

Schwedes CC, Carney GE (2012) Ecdysone signalling in adult Drosophila melanogaster. J Insect Physiol 58:293-302. https://doi.org/10.1016/j.jinsphys. 2012.01.013

Shen GM, Jiang HB, Wang XN, Wang JJ (2010) Evaluation of endogenous references for gene expression profiling in different tissues of the oriental fruit fly Bactrocera dorsalis (Diptera: Tephritidae). BMC Mol Biol 11:76. https:// doi.org/10.1186/1471-2199-11-76

Singh S (2017) Management of fruit flies on fruit crops in Punjab. Centre for Communication and International Linkages, Punjab Agricultural University, Ludhiana publication, India

Tayler A, Heschuk D, Giesbrecht D, Park JY, Whyard S (2019) Efficiency of RNA interference is improved by knockdown of dsRNA nucleases in tephritid fruit flies. Open Biol. 9(12):190198. https://doi.org/10.1098/rsob.190198

Tomoyasu Y, Miller SC, Tomita S, Schoppmeier M, Grossmann D, Bucher G (2008) Exploring systemic RNA interference in insects: a genome-wide survey for RNAi genes in Tribolium. Genome Biol 9:10

Varkouhi AK, Scholte M, Storm G, Haisma HJ (2011) Endosomal escape pathways for delivery of biologicals. J Control Release 151:220-228. https://doi.org/10. 1016/j.jconrel.2010.11.004

Verghese A, MAdhura HS, Kamala JPD, Stonehouse JM (2002) Fruit flies of economic significance in India, with special reference to Bactrocera dorsalis (Hendel). In: Barnes BN (ed) Proceedings 6th International Fruit Fly Symposium, 6-10 May 2002, Stellenbosch, South Africa. ARC Irene: Isteg Scientific Publisher, South Africa, pp 317-324

Wei D, Dou W, Jiang M, Wang J (2017) Oriental fruit fly Bactrocera dorsalis (Hendel). In: Wan F, Jiang M, Zhan A (eds) Biological Invasions and Its Management in China. Invading Nature - Springer Series in Invasion Ecology, Vol 11. Springer, Dordrecht

Winston WM, Sutherlin M, Wright AJ, Feinberg EH, Hunter CP (2007) Caenorhabditis elegans SID-2 is required for environmental RNA interference. Proc Natl Acad Sci USA 104:10565-10570. https://doi.org/10.1073/pnas. 0611282104

Yan T, Chen H, Sun Y, Yu X, Xia L (2016) RNA interference of the ecdysone receptor genes $E C R$ and USP in grain aphid (Sitobion avenae F.) affects its survival and fecundity upon feeding on wheat plants. Int J Mol Sci 17(12): 2098. https://doi.org/10.3390/ijms 17122098

Yu R, Xu X, Liang Y, Tian H, Pan Z, Jin S, Wang N, Zhang W (2014) The insect ecdysone receptor is a good potential target for RNAi-based pest control. Int J Biol Sci 10:1171-1180. https://doi.org/10.7150/ijbs.9598

Zheng W, Liu Y, Zheng W, Xiao Y, Zhang H (2015) Influence of the silencing sexpeptide receptor on Bactrocera dorsalis adults and offspring by feeding with ds-spr. J Asia Pacific Ent 18:477-481. https://doi.org/10.1016/j.aspen.2015.05. 004

Zhou L, Lim QE, Wan G, Too HP (2010) Normalization with genes encoding ribosomal proteins but not GAPDH provides an accurate quantification of gene expressions in neuronal differentiation of PC12 cells. BMC Genomics 11: 75. https://doi.org/10.1186/1471-2164-11-75

Zhu F, Xu J, Palli R, Ferguson J, Palli SR (2011) Ingested RNA interference for managing the populations of the Colorado potato beetle, Leptinotarsa decemlineata. Pest Manag Sci 67:175-182. https://doi.org/10.1002/ps.2048

Zhu J, Dong YC, Li P, Niu CY (2016) The effect of silencing 20E biosynthesis relative genes by feeding bacterially expressed dsRNA on the larval development of Chilo suppressalis. Sci Rep 6:28697. https://doi.org/10.1038/ srep28697

\section{Publisher's Note}

Springer Nature remains neutral with regard to jurisdictional claims in published maps and institutional affiliations.

\section{Submit your manuscript to a SpringerOpen ${ }^{\circ}$ journal and benefit from:}

- Convenient online submission

- Rigorous peer review

- Open access: articles freely available online

- High visibility within the field

Retaining the copyright to your article

Submit your next manuscript at $\boldsymbol{\nabla}$ springeropen.com 